\title{
O NOVO REGIME FISCAL E O DIREITO FUNDAMENTAL À SAÚDE: VIOLAÇÃO DA PROGRESSIVIDADE E DA PROIBIÇÃO DE RETROCESSO
}

\author{
THE “NEW TAX REGIME” AND THE FUNDAMENTAL RIGHT TO HEALTH: VIOLATION OF THE \\ PROGRESSIVENESS AND PROHIBITION OF REGRESSION
}

Hector Cury Soares ${ }^{1}$

\begin{abstract}
Resumo: Nesta pesquisa se analisa a violação da progressividade e da proibição de retrocesso em matéria de direito à saúde em face ao "Novo Regime Fiscal", instituído pela Emenda à Constituição n. 95/2016. Para tanto, expõe-se que os direitos fundamentais sociais geram custos, assim, impactam no Orçamento Público, considera-se que a mudança do indexador dos gastos públicos em saúde gerará um impacto negativo no Orçamento e, por fim, demonstra-se que o "Novo Regime Fiscal" impõe uma situação normativa mais prejudicial à efetivação do direito à saúde, com base na doutrina e dogmática constitucional. Utiliza-se uma abordagem metodológica descritiva, coletando as informações e os principais conceitos utilizados por meio de revisão bibliográfica, pesquisa documental e análise de jurisprudência. Ao final pondera-se que o art. 110, II do Ato das Disposições Constitucionais Transitórias (ADCT), do Novo Regime Fiscal, viola a Constituição da República no que concerne à progressividade do direito à saúde.
\end{abstract}

Palavras-chave: Novo Regime Fiscal. Progressividade. Proibição de retrocesso. Direito à saúde.

\begin{abstract}
This research analyzes the violation of the progressiveness and prohibition of social regression in the right to health in relation to the "New Tax Regime", established by the amendment n. 95/2016. To this end, it proves that the fundamental social rights generate costs thus impacting on the public budget, it shows that changing the indexer of the public expenditure on health will generate a negative impact on the budget and, finally, it demonstrates that the "New Tax Regime" imposes a regulatory situation more detrimental to the implementation of the right to health, on the basis of constitutional doctrine and dogmatics. It uses a descriptive methodological approach, collecting the information and key concepts used by means of bibliographical revision, documentary research and analysis of jurisprudence. At the end it demonstrates that the article 110, II of the Transitional Constitutional Provisions Act (ADCT), created by the New Tax Regime, violates the Constitution of the Republic regarding the progressivity of the right to health.
\end{abstract}

Keywords: New Tax Regime. Progressiveness. Prohibition of social regression. Right to health.

\footnotetext{
Doutor em Direito pela Universidade Federal do Rio Grande do Sul, com doutoramento sanduíche pela Universidade de Coimbra, Portugal; Mestre em Direito pela Universidade do Vale do Rio dos Sinos; Advogado licenciado. Professor Adjunto do Curso de Direito da Universidade do Pampa; Avenida Maria Anunciação Gomes Godoy, 1650, Bagé, Rio Grande do Sul, Brasil; hectorcury@gmail.com
} 


\section{Introdução}

O Projeto de Emenda à Constituição (PEC), que tramitou sob o número 55 no Senado e o número 241 na Câmara dos Deputados, foi aprovado no Senado no dia 13 de dezembro de 2016, em segundo turno. Foi instituído o chamado "Novo Regime Fiscal", inserindo os artigos 106, 107, 108, 109, 110, 111, 112, 113 e 114 ao Ato das Disposições Constitucionais Transitórias (ADCT) da Constituição da República (Emenda à Constituição n. 95).

Todo o projeto foi tomado de grande polêmica, pois a referida PEC, sob a égide da necessidade de promover uma mudança nos rumos das contas públicas brasileiras, propôs a limitação ao aumento da despesa primária (CÂMARA DOS DEPUTADOS, 2016).

O reflexo dessa limitação é a impossibilidade de aumento real - acima da inflação - no âmbito das contas públicas por 20 exercícios financeiros (CÂMARA DOS DEPUTADOS, 2016). Ademais, e aqui reside a polêmica esposada nesta pesquisa, a Emenda à Constituição (EC) estabelece limites aos gastos no campo da saúde, conforme o art. 110 do ADCT:

art. 110. Na vigência do Novo Regime Fiscal, as aplicações mínimas em ações e serviços públicos de saúde e em manutenção e desenvolvimento do ensino equivalerão: I - no exercício de 2017, às aplicações mínimas calculadas nos termos do inciso I do $\int 2^{\circ}$ do art. 198 e do caput do art. 212, da Constituição Federal; e II - nos exercícios posteriores, aos valores calculados para as aplicações mínimas do exercício imediatamente anterior, corrigidos na forma estabelecida pelo inciso II do $\$ 1^{\circ}$ do art. 102 deste Ato das Disposições Constitucionais Transitórias.

A justificativa do Poder Executivo é a deterioração no resultado primário das contas públicas nos últimos anos, gerando um déficit de cerca de $\mathrm{R} \$ 170$ bilhões se considerado apenas o ano 2016. Nesse sentido, a raiz do problema fiscal brasileiro estaria no crescimento acelerado da despesa primária. No âmbito político, o significado da EC 95/2016 é a retomada do ideário neoliberal para as políticas públicas brasileiras, naquilo que outrora foi caracterizado como "crise do Estado".

Todavia, a presente pesquisa visa apresentar que, do ponto de vista dogmático-jurídico, a limitação dos gastos em saúde, estabelecido pelo artigo 110, inciso II da ADCT, viola a cláusula de progressividade dos direitos sociais, presente no art. $2^{\circ}$, item 1, do Pacto Internacional de Direitos Econômicos, Sociais e Culturais e na Constituição da República.

Para comprovar a hipótese de pesquisa, adota-se uma abordagem metodológica descritiva, investigando os principais conceitos e delineamentos adotados pelo tema na doutrina pátria e estrangeira, coletando-os mediante pesquisa documental e revisão bibliográfica.

Dessa maneira, o trabalho estrutura-se abordando, em primeiro lugar, a relação entre os custos dos direitos fundamentais dentro do Orçamento Público; em segundo lugar, a constitucionalidade da cláusula de progressividade e seu reconhecimento pelo Estado brasileiro; por fim, os possíveis impactos da Emenda Constitucional n. 95 na saúde, como obstáculo à progressividade dos direitos fundamentais sociais. Ao final restará demonstrado que a Emenda à Constituição 95/2016, 
que incorporou ao ADCT o art. 110, II é inconstitucional por violar a progressividade do direito prestacional à saúde.

\section{A importância da teoria dos custos dos Direitos}

O congelamento das despesas primárias, que afetarão diretamente a educação e a saúde no Brasil, corrobora uma tese há muito defendida no âmbito da Teoria Geral dos Direitos Fundamentais (SOARES, 2015), que é preciso dispor de recursos no Orçamento Público para efetivar direitos fundamentais. Essa necessidade acentua-se no caso dos direitos sociais prestacionais, pois estes implicam prestações positivas do Estado, que geram serviços e produtos disponíveis gratuitamente aos cidadãos.

Na seara doutrinária, a obra The Cost of Rights: why liberty depends on taxes, de Holmes e Sunstein, surgiu como um marco para a Teoria dos Direitos Fundamentais ao demonstrar que todos os direitos são positivos, no sentido de que todos eles, independentemente de serem direitos de liberdade ou direitos econômicos, sociais e culturais, geram custos ao Estado (HOLMES; SUNSTEIN, 2000 , p. 35). Os autores expõem as fragilidades dessa dicotomia ao dizerem que quase todo o direito tem um dever correlato e os deveres somente são cumpridos quando há a possibilidade de o Poder Público fazê-los serem cumpridos, havendo, para tanto, a necessidade do desembolso de recursos do Estado (HOLMES; SUNSTEIN, 2000, p. 38).

A tese de Holmes e Sunstein está correta se considerar que as liberdades públicas demandam prestações positivas que assegurem o seu exercício. Se for examinada, no Brasil, a totalidade de recursos que são destinados ao Poder Judiciário, às polícias e ao custeio das eleições periódicas, perceber-se-á o quão significativo é o custo dos direitos de liberdade, tanto quanto os direitos econômicos, sociais e culturais (JUNIOR, 2009, p. 59). Portanto, para se efetivarem quaisquer direitos fundamentais são necessários investimentos por parte do Estado.

Além dos autores estadunidenses, o Professor da Universidade de Coimbra José Casalta Nabais desenvolve, em sua tese de doutoramento e estudos posteriores, aquilo que convencionou chamar de "face oculta dos direitos fundamentais", quais sejam os deveres fundamentais. Como dever fundamental principal surge o pagamento de impostos, responsável pelo sustento das políticas estatais. Em outras palavras, os cidadãos são os responsáveis pela sustentação, em termos de finanças públicas, do Estado, para que esse último possa efetivar direitos fundamentais. Além de Nabais (2008), Alexy (2008, p. 455), Arango (2012) e outros (FABRE, 2004; GALDINO, 2005; AMARAL, 2001; SCHULTZ, 2014) concordam com a importância de se levar em conta o custo dos direitos fundamentais como um dos elementos para a sua concretização.

Sob o ponto de vista dogmático, a Constituição da República garante a fonte de financiamento das despesas públicas no seu Título VI, Capítulo I, que trata do Sistema Tributário Nacional, reforçando a tese da importância de se assegurar uma fonte de financiamento aos direitos fundamentais. 
Se por um lado os direitos geram custos, por outro lado o Estado deve assegurar que os recursos sejam suficientes para a promoção de uma condição digna aos indivíduos. Nesse sentido, independentemente da geração/dimensão, os direitos fundamentais gozam de igual força em face ao orçamento, principalmente se se considerar a desigualdade não só presente na realidade brasileira, mas comum a todos os Estados latino-americanos (ARANGO, 2010).

Dessa forma, o Estado conta com um orçamento para atender ao controle dos gastos públicos, reafirmando a própria condição de Estado Democrático de Direito (art. $1^{\circ}$ ) (TORRES, 2000, p. 19). No orçamento são discriminadas as receitas e despesas públicas, que devem prezar pelo equilíbrio dos gastos de maneira a permitir a efetivação dos direitos prestacionais sociais. Em outras palavras, a disponibilização orçamentária gera serviços aos usuários da educação e do Sistema Único de Saúde (SUS).

$\mathrm{Na}$ Constituição da República, o plano plurianual (PPA), a Lei de Diretrizes Orçamentárias (LDO) e a Lei Orçamentária Anual (LOA) são os meios utilizados pelo Estado para planejar a sua ação; é na LOA, entretanto, que há a aplicação concreta de recursos na efetivação de direitos. No art. 165, \8, e no art. 167 (BRASIL, 2013), há a disposição de que os recursos que o Estado prevê arrecadar e as despesas que estará autorizado a realizar devem constar no orçamento anual. Assim, o orçamento assegura o confronto entre os recursos possíveis e as despesas necessárias.

A aplicação de recursos tem como consequência a escolha de áreas, programas e projetos que sejam considerados prioritários na efetivação do direito prestacional à saúde; a escolha política adotada é corporificada com a LOA. No caso da saúde, a Constituição assegura uma estrutura financeira mínima à efetivação do seu direito, além da estrutura para a operacionalização das prestações: o SUS.

Não há recursos disponíveis para todas as necessidades em termos de saúde pública, por isso são feitas escolhas políticas na alocação desses recursos - escolhas estas que não devem ser feitas arbitrariamente, mas a partir de parâmetros que as justifiquem constitucionalmente. A definição, por exemplo, dos medicamentos que serão disponibilizados ou de tratamentos que serão providos pelo SUS passa pela previsão de recursos destinados a essas prestações.

É com base nas previsões orçamentárias em relação às despesas e receitas que o Estado pode corporificar o direito prestacional à saúde por meio de políticas públicas de saúde. Salienta-se a lição de Sunstein e Holmes (2000, p. 19): "A legal right exists, in reality, only when and if it has budgetary costs." É preciso reforçar a importância do custo do direito à saúde como um elemento essencial para sua efetivação, sem marginalizar os parâmetros mínimos estabelecidos na Constituição.

Isso posto, é possível concluir que: a) todos os direitos fundamentais geram custos; b) o direito prestacional à saúde gera custos ao Estado; c) para financiar os serviços e infra-estrutura pública em saúde, o Estado dispõe de um Orçamento no qual são alocadas demandas consideradas prioritárias. Na próxima seção, passa-se a examinar os desdobramentos, em termos de prestações, com o congelamento de recursos voltados ao direito à saúde. 


\section{A escassez de recursos para a saúde com a EC n. 95/2016}

O "Orçamento da Saúde", segundo a Constituição da República, prevê recursos mínimos que devem ser aplicados a gastos de saúde, direcionados a cada ente federativo, como ocorre no art.

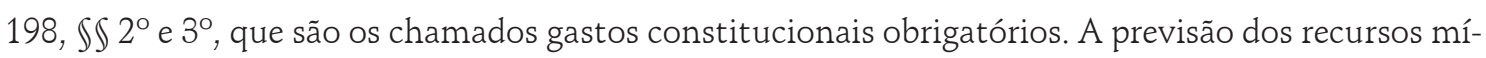
nimos é fruto da Emenda Constitucional n. 29/2000, e a regulamentação dos percentuais mínimos ocorreu em 2012, por meio da Lei Complementar n. 141/2012 (BRASIL, 2012). No caso da União, a Lei Complementar garante o escalonamento, entre os anos 2016 e 2020, da aplicação de um percentual de receita corrente líquida alcançando, ao final, os $15 \%$ do art. $198, \mathbb{\$} 2^{\circ}$, I da Constituição da República, conforme o art. $2^{\circ}$ da EC 86/2016:

Art. $2^{\circ} \mathrm{O}$ disposto no inciso I do $\$ 2^{\circ}$ do art. 198 da Constituição Federal será cumprido progressivamente, garantidos, no mínimo: I - 13,2\% (treze inteiros e dois décimos por cento) da receita corrente líquida no primeiro exercício financeiro subsequente ao da promulgação desta Emenda Constitucional; II - 13,7\% (treze inteiros e sete décimos por cento) da receita corrente líquida no segundo exercício financeiro subsequente ao da promulgação desta Emenda Constitucional; III $14,1 \%$ (quatorze inteiros e um décimo por cento) da receita corrente líquida no terceiro exercício financeiro subsequente ao da promulgação desta Emenda Constitucional; IV - 14,5\% (quatorze inteiros e cinco décimos por cento) da receita corrente líquida no quarto exercício financeiro subsequente ao da promulgação desta Emenda Constitucional; V - 15\% (quinze por cento) da receita corrente líquida no quinto exercício financeiro subsequente ao da promulgação desta Emenda Constitucional. (BRASIL, 2015).

Atualmente, para reajustar os valores, a União deve destinar às ações e aos serviços na área da saúde (direito prestacional à saúde) o montante aplicado em um ano, com acréscimo anual correspondente à variação do PIB no mesmo período (MARTINS, 2011, p. 811).

Entretanto, com o regime adotado pela Emenda à Constituição n. 95/2016, os gastos constitucionais obrigatórios em saúde são mantidos, sendo a sua recomposição feita levando em consideração o Índice Nacional de Preços ao Consumidor Amplo (IPCA), conforme o art. 110, II do ADCT. Mantêm-se os gastos constitucionais obrigatórios, alterando o indexador. Questiona-se: há sustentabilidade (financeira) de um modelo de acesso universal nesses moldes? A resposta está em verificar se tal mudança potencializa a escassez de meios econômico-financeiros no âmbito da saúde (LOUREIRO, 2010, p. 59-60).

Em primeiro lugar, o modelo adotado pela EC desconsidera dados epidemiológicos ou demográficos do Brasil. No campo do direito prestacional à saúde, é preciso considerar que há determinantes multidimensionais e complexos que demandam políticas públicas cada vez mais elaboradas e que envolvem diferentes setores, como, por exemplo,

um estudo sobre as doenças respiratórias agudas em menores de 5 anos, publicado recentemente, revelou que o risco da mortalidade por pneumonia na região do Butantã, em São Paulo, foi significativamente maior entre 1991 e 1997 nas crian- 
ças com piores condições socioeconômicas, incluindo-se as condições de moradia. (FERRAZ; VIEIRA, 2009, p. 225).

Em segundo lugar, o "Novo Regime Fiscal" é dúbio, pois não deixa claro, no caso da saúde, se há a revogação do escalonamento previsto pela EC n. 86/2015 e qual será o percentual mínimo a ser aplicado a partir de 2017. Não fica evidenciado se será aplicado o percentual de 13,2\% ou de 15\%, conforme a EC n. 86/2015.

Em terceiro lugar, a mudança da correção da variação do Produto Interno Bruto (PIB) para a variação do IPCA resultará no encolhimento do "Orçamento da Saúde" durante a vigência da EC n. 95/2016. Para se ter ideia, um estudo recente (BENEVIDES; VIEIRA, 2016) demonstrou que se entre 2003 e 2015 fosse aplicada a regra da EC n. 96/2016, haveria uma perda de 42,1\% no orçamento. Assim,

[e]nquanto a regra da EC 29 protegia o orçamento federal do SUS por meio da correção pela variação nominal do PIB, a regra proposta na PEC 241 incorpora apenas a correção pela inflação, desconsiderando a incorporação das taxas de crescimento da economia ao gasto com saúde e reduzindo a participação do gasto com saúde no PIB. (BENEVIDES; VIEIRA, 2016, p. 9).

Ainda, se examinada a vinculação ao PIB ou IPCA ao longo de 20 anos, considerando uma média de crescimento de PIB na casa de $2 \%$ ao ano, estima-se uma perda na saúde de cerca de 654 bilhões de reais acumulada no período (BENEVIDES; VIEIRA, 2016, p. 12). Quanto melhor o desempenho da economia brasileira nos próximos 20 anos, maiores serão as perdas no Orçamento da Saúde, em virtude da mudança do indexador. O único cenário em que o IPCA preponderaria em relação ao PIB é no caso de não haver crescimento econômico durante os 20 anos e com a aplicação de $15 \%$ das receitas correntes líquidas ao ano, ou seja, algo improvável.

Em quarto lugar, o Instituto Brasileiro de Estatística e Geografia (IBGE) apresentou estudo de projeção da população brasileira, que demonstrou a possibilidade de crescimento positivo até 2042, com cerca de 228 milhões de habitantes. Levando em consideração o período de vigência da EC n. 95/2016, em 2036 a população será de cerca de 226 milhões de habitantes (IBGE, 2016). Com o crescimento populacional e a adoção de novos parâmetros para a variação do gasto em saúde, estima-se que o gasto per capita em 2036 será de R \$ 411. Em sentido oposto, se mantido o regime da EC n. 86/2015 e o crescimento do PIB em 0,0\%, o gasto per capita em 2036 será de R \$ 460, podendo ser maior em caso de crescimento do PIB (BENEVIDES; VIEIRA, 2016, p. 12).

Em quinto lugar e em conformidade com o argumento anterior, o Novo Regime Fiscal implica a desobrigação por parte dos governos a investir em saúde pública em caso de crescimento econômico. Ainda que a economia brasileira "saia do vermelho", não há nenhuma vinculação do nível de investimento em saúde ao crescimento do PIB. Encaminha-se, rapidamente, para o aprofundamento das iniquidades no acesso à saúde no Brasil.

Nesse cenário, o Administrador Público obriga-se a realizar escolhas trágicas na efetivação do direito prestacional à saúde, ou seja, decisões em que a alocação de recursos em um determina- 
do programa representa a não alocação em outro programa governamental de saúde (CALABRESI; BOBBITT, 2000, p. 19) Nas palavras dos autores, "the progression from attempt to desperate attempt to avoid tragedy that forms the sequence of decision in the tragic choices" (CALABRESI; BOBBITT, 2000, p. 21) caracteriza as escolhas trágicas. São essas escolhas que necessariamente deixarão desamparada parte da população na efetivação do direito prestacional à saúde.

Em sexto lugar, a limitação dos gastos públicos em saúde onerará as famílias mais pobres, tendo em vista que o SUS é fator que diminui de peso do custo da saúde na composição do orçamento familiar. Evidencia-se que "Somente 18\% dos 10\% mais pobres residiam em famílias que tiveram dispêndios com medicamentos, sendo de $57 \%$ a fração equivalente entre os $10 \%$ mais ricos." (SILVEIRA; OSÓRIO; PIOLA, 2002, p. 728). Além disso, trata-se de umas das metas de desenvolvimento sustentável da Organização das Nações Unidas (ONU) a ampliação do investimento público em saúde desonerando as famílias mais pobres (ORGANIZAÇÃO DAS NAÇÕES UNIDAS, 2015). É preciso dizer, também, que o não reajustamento das tabelas de procedimentos do SUS tem sido uma forma de precarização dos serviços, por via incidental.

Conclui-se que: a) a EC n. 95/2016 altera a forma de indexação e financiamento do direito à saúde; b) o novo indexador compromete a ampliação e manutenção dos serviços no âmbito da saúde pública, gerando, ao longo do período de vigência, uma diminuição do gasto público per capita no Brasil; c) e a escassez de recursos levará a escolhas trágicas e ao aprofundamento das desigualdades no acesso à saúde no Brasil. Na seção seguinte, passa-se a analisar a progressividade do direito social à saúde.

\section{A progressividade - proibição de retrocesso - dos direitos sociais}

Nesta seção, pretende-se demonstrar que, se consideradas verdadeiras as premissas das seções 2 e 3 da presente pesquisa, o art. 110, II do ADCT carece de constitucionalidade por violar a progressividade do direito prestacional à saúde e a proibição de retrocesso. Para tanto, a seguir ressalta-se a presença da progressividade na Constituição da República e a sua violação pela EC n. 95/2016.

O Brasil é signatário do Pacto Internacional de Direitos Econômicos, Sociais e Culturais (PIDESC) (BRASIL, 1992), que passou ao ordenamento jurídico pátrio por meio do Decreto n. 591, de 06 de julho de 1992. O PIDESC, que data de 1966, é fruto dos desdobramentos dos princípios da Carta das Nações Unidas e decorrência, segundo o texto do preâmbulo, da necessidade de assegurar a dignidade inerente à pessoa humana.

Ao ser internalizado, o PIDESC adquire efeito de norma constitucional estabelecendo uma série de deveres ao Estado brasileiro na esfera dos direitos fundamentais sociais. Sobre o tema há a importante contribuição do Prof. Antonio Augusto Cançado Trindade (1997, p. 498):

O disposto no artigo $5^{\circ}$, parágrafo $2^{\circ}$ da Constituição brasileira de 1988 se insere na nova tendência de Constituições latino-americanas recentes de conceder um tratamento especial ou diferenciado também no plano do direito interno aos direitos e garantias individuais internacionalmente consagrados. A especificidade 
e o caráter especial dos tratados de proteção internacional dos direitos humanos encontram-se, com efeito, reconhecidos e sancionados pela Constituição brasileira de 1988: se para os tratados internacionais em geral, se tem exigido a intermediação pelo Poder Legislativo de ato com força de lei de modo a outorgar a suas disposições vigência ou obrigatoriedade no plano do ordenamento jurídico interno, distintamente no caso dos tratados de proteção internacional dos direitos humanos em que o Brasil é Parte os direitos fundamentais neles garantidos passam, consoante os artigos 5(2) e 5(1) da Constituição brasileira de 1988, a integrar o elenco dos direitos constitucionalmente consagrados e direta e imediatamente exigíveis no plano do ordenamento jurídico interno. ${ }^{2}$

No mesmo sentido, a dogmática brasileira e a doutrina não descartam a possibilidade da existência de direitos fundamentais que não estão incluídos no catálogo constitucional (VIEIRA DE ANDRADE, 2012, p. 75), mas que ainda assim podem ser considerados de forma implícita (GRAU, 2006, p. 85; ÁVILA, 2012, p. 33-34; GUASTINI, 2011, p. 8-9; HESSE, 1998, p. 43-44), como é o casso do art. $2^{\circ}$, item 1 do PIDESC. Além disso, a progressividade dos direitos sociais e a proibição de retrocesso são corolários do Estado Democrático de Direito (art. $1^{\circ}$ da Constituição da República), inerentes à ideia da força normativa da Constituição e do conteúdo mínimo dos direitos fundamentais sociais (SARLET, 2006, p. 345-346). Sendo esta a sustentação dogmática apresentada para a internalização da progressividade na ordem constitucional brasileira. Todavia, é importante ressaltar a crítica de Novais (2010, p. 359-360) de que a progressividade - ou proibição de retrocesso - não é uma cláusula absoluta, devendo ponderar as condições e os argumentos apresentados pelo Estado que, por sua vez, deverá assegurar o mínimo em prestações materiais no campo dos direitos sociais.

Segundo o art. $2^{\circ}$, item 1 do PIDESC, os Estados signatários assumem o dever de adotar medidas para implementar progressivamente os direitos reconhecidos no pacto:

Cada Estado Parte do presente Pacto compromete-se a adotar medidas, tanto por esforço próprio como pela assistência e cooperação internacionais, principalmente nos planos econômico e técnico, até o máximo de seus recursos disponíveis, que visem a assegurar, progressivamente, por todos os meios apropriados, o pleno exercício dos direitos reconhecidos no presente Pacto, incluindo, em particular, a adoção de medidas legislativas. (SARLET, 2006, p. 345-346).

Esse artigo é interpretado como uma cláusula de progressividade ou proibição de retrocesso dos direitos constantes no PIDESC, entre eles o direito à saúde (art. 12), de forma a assegurar a sua realização progressiva. Entende-se que tal regime se aplica ao direito à saúde no Brasil, obrigando o Estado a não adotar medidas e políticas ou mesmo mudanças no âmbito legislativo que possam eventualmente piorar a situação dos indivíduos (PISARELLO, 2007, p. 62). É o mesmo entendimento do Comitê de Direitos Econômicos, Sociais e Culturais das Nações Unidas, em suas próprias palavras:

Moreover, any deliberately retrogressive measures in that regard would require the most careful consideration and would need to be fully justified by reference to the totality of

\footnotetext{
2 Embora não se trate de tema tomado de univocidade, a perspectiva que se pauta a pesquisa tem sustentação na doutrina pátria a qual, por questões epistemológicas, é adotada. No mesmo sentido aqui esposado: Trindade (1991, p. 631). Ademais, no mesmo sentido: Piovesan (2013) e Sarlet (2010).
} 
the rights provided for in the Covenant and in the context of the full use of the maximum available resources. (UNITED NATIONS, 2014).

Na doutrina (CANOTILHO, 2004, p. 475; SARLET, 2010; ARANGO, 2012), a ideia que permeia os princípios é perfeitamente resumida por Pisarello (2007, p. 63) ao dizer que a proibição de regresso significa que o direito prestacional à saúde, quando regulado pelo Poder Executivo - que estabelece as prestações por meio de políticas públicas - introduz um núcleo essencial, intangível, de necessidades básicas que o legislador não deve modificar em um sentido regressivo. Isso representa, de maneira geral, uma situação menos favorável ao titular do direito.

Nesse sentido, Courtis (2006, p. 3-4) aponta dois caminhos possíveis à aplicação da progressividade (proibição do retrocesso): 1) ligado aos resultados de uma política pública (regressividade de resultados), caso em que os resultados das políticas públicas ficam abaixo da expectativa inicial, apontando retrocesso em relação ao cenário inicial; 2) ligado ao chamado retrocesso normativo, em relação à extensão dos direitos concedidos por uma norma.

Na perspectiva normativa não há um exame fático, mas uma comparação com a norma que substitui e uma avaliação de se esta suprime, limita ou restringe direitos ou benefícios concedidos anteriormente (COURTIS, 2006, p. 4). Ambos os sentidos propostos por Courtis são abarcados pelo PIDESC. Em relação à regressividade dos resultados de políticas públicas, é possível estabelecer indicadores que apontem índices de satisfação, por exemplo, em relação aos serviços de saúde (COURTIS, 2006, p. 5).

O exame que se pretende fazer aqui é em relação ao retrocesso normativo que o art. 110, II do ADCT impõe ao direito prestacional à saúde. Por certo a progressividade não impede que sejam revistas políticas públicas de saúde, porém não autoriza um "cheque em branco" ao legislador. O resultado é que toda a modificação na Constituição da República deverá redundar numa maior proteção ao direito à saúde (PISARELLO, 2007, p. 66). Trata-se de um dever que impõe a obrigação concreta da realização do máximo de esforços e recursos, inclusive financeiros, para a satisfação de um conteúdo mínimo do direito fundamental (PISARELLO, 2007, p. 66; OUEIROZ, 2006, p. 72-73; SUNSTEIN, 2006, p. 12; BRASIL, 2012).

Com base nos arts. 196 e seguintes da Constituição da República e nas Emendas à Constituição n. 86/2015 e 95/2016, procura-se evidenciar se a alteração normativa, no campo do financiamento da saúde, viola a cláusula de progressividade (e retrocesso) do direito prestacional à saúde. 
Quadro 1 - Forma de financiamento da saúde pública no Brasil anterior à EC n. 95/2016

\begin{tabular}{|c|c|}
\hline Conteúdo essencial & orma normativa de financiamento \\
\hline $\begin{array}{l}\text { (1) Acesso de todos ao Sistema } \\
\text { Único de Saúde. } \\
\text { (2) A prestação dos serviços é } \\
\text { dever do Estado. } \\
\text { (3) O Estado deve definir polí- } \\
\text { ticas públicas para sua efetiva- } \\
\text { ção. } \\
\text { (4) A saúde deve ser interpreta- } \\
\text { da na sua integralidade. } \\
\text { (5) O acesso aos serviços é uni- } \\
\text { versal e acesso igualitário. }\end{array}$ & $\begin{array}{l}\text { (1) A União garante o escalonamento, entre os anos } 2016 \text { e } 2020 \text {, da aplicação de um } \\
\text { percentual de receita corrente líquida, alcançando, ao final, os } 15 \% \text { do art. } 198, \sqrt{ } 2^{\circ} \text {, I } \\
\text { da Constituição da República, conforme o art. } 2^{\circ} \text { da EC n. } 86 / 2016 \text { e distribuídos da } \\
\text { seguinte maneira: } \\
\text { (1.1) } 13,2 \% \text { da receita corrente líquida em } 2016 \text {; } \\
\text { (1.2) } 13,7 \% \text { da receita corrente líquida em } 2017 ; \\
\text { (1.3) } 14,1 \% \text { da receita corrente líquida em } 2018 ; \\
\text { (1.4) } 14,5 \% \text { da receita corrente líquida em } 2019 ; \\
\text { (1.5) } 15 \% \text { da receita corrente líquida em } 2020 \text {. } \\
\text { (2) A previsão orçamentária de despesas na área da saúde não deve ser inferior ao valor } \\
\text { empenhado no exercício financeiro anterior e deve receber um aumento, no mínimo, } \\
\text { de acordo com a variação do PIB em relação à União (art. } 5^{\circ} \text { da Lei Complementar n. } \\
\text { 141/2012). }\end{array}$ \\
\hline
\end{tabular}

Fonte: o autor.

No Quadro 1, que ilustra o regime anterior à EC n. 95/2016, o dever de progressividade normativo é cumprido ao garantir um investimento contínuo e ascendente (SOARES, 2014, p. 125-126) no campo do financiamento da saúde. Além disso, assegura que, no caso de crescimento econômico, exista a vinculação dos Poderes Executivos e Legislativos para o incremento do orçamento da saúde. No entanto, o "Novo Regime Fiscal" apresenta uma nova fórmula normativa para o financiamento da saúde:

Quadro 2 - Forma de financiamento da saúde pública no Brasil com base na EC n. 95/2016

\begin{tabular}{|c|c|}
\hline Conteúdo essencial & Forma normativa de financiamento \\
\hline $\begin{array}{l}\text { (1) Acesso a todos ao Sistema Único de Saúde. } \\
\text { (2) A prestação dos serviços é dever do Estado. } \\
\text { (3) O Estado deve definir políticas públicas para sua } \\
\text { efetivação. } \\
\text { (4) A saúde deve ser interpretada na sua integrali- } \\
\text { dade. } \\
\text { (5) O acesso aos serviços é universal e acesso igua- } \\
\text { litário. }\end{array}$ & $\begin{array}{l}\text { (1) Os gastos constitucionais obrigatórios em saúde são mantidos, } \\
\text { contudo a sua recomposição será feita levando em consideração o } \\
\text { Índice Nacional de Preços ao Consumidor Amplo (IPCA), confor- } \\
\text { me o art. 110, II da ADCT. } \\
\text { (2) O Novo Regime Fiscal tem um período de vigência de } 20 \text { exer- } \\
\text { cícios financeiros. }\end{array}$ \\
\hline
\end{tabular}

Fonte: o autor.

Considerado o Quadro 2, é perceptível, com base nos dados trabalhados na seção 2, que a alteração normativa na forma de financiamento da saúde pública no Brasil estabelece uma situação mais prejudicial aos usuários do serviço. Além de ser obtusa em relação à EC n. 86/2015 e de desvincular o Legislador e o Executivo do crescimento econômico do Brasil, desconsidera os dados demográficos que apontam um decréscimo do valor per capita investido em saúde.

A existência de uma crise econômica no Brasil não deve justificar qualquer atentado à Constituição (SARLET, 2014, p. 278-279); o contexto de crise é um espaço para reforçar a importância dos direitos sociais na construção de um Estado sem desigualdades. As palavras do Prof. João Loureiro (2010, p. 11) reforçam o argumento: "E, mesmo argumentando-se que está em causa a 'sal- 
vação de uma vida humana', adverte-se que 'o princípio económico se sobrepõe a tudo' e que importa atrair capitais estrangeiros."

Nesse sentido, conclui-se que: a) o Brasil incorporou a sua Constituição a cláusula de progressividade (e proibição de retrocesso) no campo dos direitos fundamentais sociais; e b) o art. 110, II do ADCT estabelece, normativamente, uma forma de financiamento à saúde que implica violação à cláusula de progressividade carecendo, portanto, de constitucionalidade.

\section{Considerações finais}

É pauta recorrente dos Poderes Executivo e Legislativo a resistência à efetivação dos direitos fundamentais sociais previstos na Constituição da República. Desde a Assembleia Constituinte (1987-1988), declarações como a do então Presidente da República José Sarney, em 25 de novembro de 1987, ao jornal O Globo: "Constituição tornará País ingovernável" (SARNEY, 1987) retratam a relutância em assegurar os direitos sociais no País. Sarney referia-se aos graves problemas sociais do País e de como a imposição de uma agenda de direitos prestacionais traria dificuldade para se governar.

Quando Fernando Collor de Mello (1990-1992) assumiu a Presidência da República do Brasil, encontrou o País submerso na chamada hiperinflação e, com apoio do Fundo Monetário Internacional (FMI), deu início a uma série de tentativas fracassadas de controle econômico do País, muitas vezes de forma ortodoxa e violenta. Por consequência, houve a necessidade de ajuste fiscal, na tentativa de reduzir drasticamente o gasto público, confrontando-se o programa constitucional ao programa neoliberal (SADER, 2009, p. 62). Ainda na década de 1990, o Governo Fernando Henrique Cardoso, pautado pela agenda neoliberal, propôs 18 Emendas à Constituição que representaram retrocesso em termos de direitos fundamentais sociais (COUTO, 2006, p. 51).

No Governo ilegítimo de Michel Temer (2016) é lançado, como base para o seu governo, um documento chamado "Uma Ponte para o Futuro" (PARTIDO DO MOVIMENTO DEMOCRÁTICO BRASILEIRO, 2017) que, em suma, retoma o ideário neoliberal e estabelece um severo ajuste fiscal ao Brasil. Efetivamente, representa a desregulamentação de direitos fundamentais sociais previstos na Constituição da República.

A relação do dito à guisa de considerações finais com o tema esposado na pesquisa é bem simples: existe uma "ponte" entre a política institucional e a Constituição da República. E, para que a política institucional neoliberal possa prosperar, é preciso penalizar os direitos fundamentais sociais. É exatamente dentro dessa perspectiva que surge o "Novo Regime Fiscal" (Emenda à Constituição n. 95/2016).

Entretanto, pode-se perceber ao longo do texto que, para além de diatribes políticas que visam desconstruir o Estado Democrático de Direito, há também questões dogmático-jurídicas que 
são atravessadas pela EC n. 95/2016. Uma delas é o art. 110, II do ADCT, pois ao ser estabelecido um novo indexador para os gastos públicos em saúde, o IPCA, os Poderes Executivo e Legislativo criam uma situação normativa mais prejudicial aos destinatários do direito prestacional à saúde.

Como visto, os dados demográficos e as estimativas econômicas apontam para um retrocesso em termos de efetivação do direito prestacional à saúde com a perspectiva de crescimento populacional e o encolhimento do gasto per capita com a saúde pública. Esse retrocesso representa violação à cláusula de progressividade do direito prestacional à saúde, conforme art. 2, item 1 e art. 12 do PIDESC. Deve ser considerada, para tanto, a incorporação às normas constitucionais de forma implícita ou pela ratificação de um tratado que verse acerca de matéria de direitos humanos, respectivamente, art. $5^{\circ}$, parágrafos primeiro e segundo da Constituição da República.

Além disso, da análise dos dispositivos constitucionais anteriores à EC n. 95/2016 e posteriores, é criada uma forma de financiamento mais prejudicial e incapaz de atender normativa e faticamente ao regime jurídico estabelecido nos arts. 196 e seguintes da Constituição da República. Em 2018, quando a conquista do SUS completa 30 anos, caminha-se a passos largos ao seu desmantelamento de algo que é ainda uma promessa não cumprida para muitos, tendo em vista a dependência de outras fontes de financiamento, como, por exemplo, o subsídio à saúde suplementar via dedução do Imposto de Renda Pessoa Física.

Portanto, conclui-se que a Constituição da República e o Estado Social brasileiro não devem ficar sujeitos às mudanças políticas. O exercício do Poder Constituinte Derivado Reformador não torna a Constituição e os direitos fundamentais sociais livremente alteráveis. E, nesse sentido, o art. 110, II do ADCT viola a progressividade e a proibição de retrocesso no campo do direito prestacional à saúde, e como decorrência viola os arts. 196 e 198 da Constituição da República.

\section{Referências}

ALEXY, Robert. Teoría de los derechos fundamentales. Madrid: Centro de Estudíos Politicos y Constitucionales, 2008.

AMARAL, Gustavo. Direito, escassez \& escolha. Rio de Janeiro: Renovar, 2001.

ARANGO, Rodolfo. El Concepto de Derechos Sociales Fundamentales. Bogotá: Legis, 2012.

ARANGO, Rodolfo. Los derechos sociales en iberoamérica: estado de la cuestión y perspectiva de futuro. Cuadernos eletrónicos de Derechos Humanos y Democracia, n. 5, fev. 2010. Disponível em: <http://www.portalfio.org/inicio/archivos/cuadernos_electronicos/numero_5/1_\%20Los\%20derechos\%20sociales\%20en\%20Iberoam\%C3\%A9rica.pdf>. Acesso: 08 dez. 2013.

ÁVILA, Humberto Bergmann. Teoria dos Princípios: da definição à aplicação dos princípios jurídicos. São Paulo: Malheiros, 2012. 
BENEVIDES, Rodrigo Pucci de Sá e; VIEIRA, Fabíola Sulpino. Os Impactos do Novo Regime Fiscal para o Financiamento do Sistema Único de Saúde e para a Efetivação do Direito à Saúde no Brasil. Nota Técnica n 28/2016. Instituto de Pesquisa Econômica Aplicada (IPEA). Disponível em: <http:// www.ipea.gov.br/portal/images/stories/PDFs/nota_tecnica/160920_nt_28_disoc.pdf $>$. Acesso em: 17 dez. 2016.

BRASIL. Constituição. República Federativa do Brasil de 1988. Brasília, DF: Senado Federal, 05 out. 1988. Disponível em: <http://www.planalto.gov.br/ccivil_03/constituicao/constituicao.htm>. Acesso em: 02 dez. 2013.

BRASIL. Decreto n. 591, de 06 de julho de 1992. Atos Internacionais. Pacto Internacional sobre Direitos Econômicos, Sociais e Culturais. Promulgação. Diário Oficial da União, Brasília, DF, 07 jul. 1992. Disponível em: <https://www.planalto.gov.br/ccivil_03/decreto/1990-1994/d0591.htm>. Acesso em: 04 jan. 2017.

BRASIL. Emenda à Constituição n. 86, de 17 de março de 2015. Altera os arts. 165, 166 e 198 da Constituição Federal, para tornar obrigatória a execução da programação orçamentária que especifica. Diário Oficial da União, 18 mar. 2015. Disponível em: <http://www.planalto.gov.br/ccivil_03/ constituicao/emendas/emc/emc86.htm >. Acesso em: 17 dez. 2016.

BRASIL. Emenda à Constituição n. 95/2016. Diário Oficial da União, 16 dez. 2016. Disponível em: $<$ http://pesquisa.in.gov.br/imprensa/jsp/visualiza/index.jsp?data=16/12/2016\&jornal=1\&pagina $=2$ \&totalArquivos=368>. Acesso em: 16 dez. 2016.

BRASIL. Lei Complementar n. 141, de 13 de janeiro de 2012. Regulamenta o $\int 3^{\circ}$ do art. 198 da Constituição Federal para dispor sobre os valores mínimos a serem aplicados anualmente pela União, Estados, Distrito Federal e Municípios em ações e serviços públicos de saúde; [...] e dá outras providências. Diário Oficial da União, 16 jan. 2012. Disponível em: <http://www.planalto.gov. br/ccivil_03/leis/lcp/Lcp141.htm>. Acesso em: 10 jan. 2014.

BRASIL. Lei n. 8.080, de 19 de setembro de 1990. Dispõe sobre as condições para a promoção, proteção e recuperação da saúde, a organização e o funcionamento dos serviços correspondentes e dá outras providências. Diário Oficial da União, 20 set. 1990. Disponível em: <http://www.planalto. gov.br/ccivil_03/leis/18080.htm> Acesso em: 03 dez. 2013.

CALABRESI, Guido; BOBBITT, Philip. Tragic Choices: the conflicts society in the allocation of tragically scarce resources. New York: Norton \& Company, 2000.

CÂMARA DE DEPUTADOS. Projeto de Emenda Constitucional no 241. Altera o Ato das Disposições Constitucionais Transitórias, para instituir o Novo Regime Fiscal. 2016. Disponível em: <http:// www.camara.gov.br/proposicoesWeb/prop_mostrarintegra;jsessionid=F5C083035789ECDE0FD8C1445955C192. proposicoesWebExterno2 ? codteor $=1468431 \&$ filename $=P E C+241 / 2016>$. Acesso em: 12 jan. 2017.

CANOTILHO, José Joaquim Gomes. Direito Constitucional e Teoria da Constituição. Coimbra: Almedina, 2004.

COURTIS, Christian. La prohibición de regresividad en materia de derechos sociales: apuntes introductorios. In: COURTIS, Christian. Ni un paso atrás: la prohibición de regresividad en materia de derechos sociales. Buenos Aires: Del Puerto, 2006. 
COUTO, Cláudio Gonçalves Couto; ARANTES, Rogério Bastos. Constituição, Governo e Democracia no Brasil. Revista Brasileira de Ciências Sociais, v. 21, n. 61, 2006.

FABRE, Cécile. Social Rights under the Constitution. Government and decent life. Oxford: Oxford, 2004.

FERRAZ, Octávio Luiz Motta; VIEIRA, Fabíola Sulpino. Direito à Saúde, Recursos Escassos e Equidade: os riscos da interpretação judicial dominante. DADOS - Revista de Ciências Sociais, v. 52, n. $1,2009$.

GALDINO, Flávio. Introdução à teoria dos custos dos direitos: direitos não nascem em árvores. Rio de Janeiro: Lumen Juris, 2005.

GRAU, Eros Roberto. Ensaio sobre a interpretação/aplicação do Direito. São Paulo: Malheiros, 2006.

GUASTINI, Riccardo. Interpretare e Argomentare. Milano: Giuffrè, 2011.

HESSE, Konrad. Elementos de Direito Constitucional da República Federal da Alemanha (Grundzüge des Verfassungsrechts der Bundesrepublik Deutschland). Porto Alegre: Sergio Antonio Fabris, 1998.

HOLMES, Stephen; SUNSTEIN, Cass R. The Cost of Rights: why liberty depends on taxes. New York: Norton, 2000.

INSTITUTO BRASILEIRO DE GEOGRAFIA E ESTATÍSTICA. Projeção da população do Brasil e das Unidades da Federação. Disponível em: <http://www.ibge.gov.br/apps/populacao/projecao/>. Acesso em: 20 dez. 2016.

JUNIOR, Alceu Maurício. A revisão judicial das escolhas orçamentárias: a intervenção judicial em políticas públicas. Belo Horizonte: Fórum, 2009.

LOUREIRO, João Carlos. Adeus ao Estado Social? Coimbra: Coimbra, 2010.

MARTINS, Marcelo Guerra. As vinculações das Receitas Públicas no Orçamento. A desvinculação das receitas da união (DRU). As contribuições e a referebilidade. In: CONTI, José Maurício; SCAFF, Fernando Facury. Orçamentos Públicos e Direito Financeiro. São Paulo: Revista dos Tribunais, 2011.

NABAIS, José Casalta. A face oculta dos direitos fundamentais: os deveres e os custos dos Direitos. In: NABAIS, José Casalta. Por uma liberdade com responsabilidade: estudo sobre os direitos e deveres fundamentais. Coimbra: Coimbra, 2007.

NOVAIS, Jorge Reis. Direitos Sociais: teoria jurídica dos Direitos Sociais enquanto Direitos Fundamentais. Coimbra: Coimbra, 2010.

PARTIDO DO MOVIMENTO DEMOCRÁTICO BRASILEIRO (PMDB). Uma Ponte para o Futuro. Disponível em: <http://pmdb.org.br/wp-content/uploads/2015/10/RELEASE-TEMER_A4-28.10. 15-Online.pdf> . Acesso em: 12 jan. 2017.

PIOVESAN, Flávia. Direitos Humanos e Direito Constitucional Internacional. São Paulo: Saraiva, 2013.

PISARELLO, Gerardo. Los derechos sociales y sus garantías. Madrid: Trotta, 2007. 
QUEIROZ, Cristina. O princípio da não reversibilidade dos Direitos Fundamentais Sociais: princípios dogmáticos e prática jurisprudencial. Coimbra: Coimbra, 2006.

SADER, Emir. A Nova Toupeira: os caminhos da esquerda latino-americana. São Paulo: Boitempo, 2009.

SARLET, Ingo Wolfgang. A eficácia dos Direitos Fundamentais. Porto Alegre: Livraria do Advogado, 2010.

SARLET, Ingo Wolfgang. Os Direitos Sociais a Prestações em Tempos de Crise. Espaço Jurídico Journal of Law, v. 15, n. 2, p. 271-284, jul./dez. 2014.

SARLET, Ingo Wolfgang. La prohibición de retroceso en derechos sociales fundamentales en Brasil: algunas notas sobre el desafio de la supervivencia de los derechos sociales en un contexto de crisis. In: COURTIS, Christian. Ni un paso atrás: la prohibición de regresividad en materia de derechos sociales. Buenos Aires: Del Puerto, 2006.

SARNEY: Constituição tornará País ingovernável. O Globo, Rio de Janeiro, p. 6, 25 nov. 1987.

SCHULTZ, Jim. Promises to Keep: using public budgets as a tool to advance economic, social and cultural rights. México: Ford Fundation and FUNDAR - Center for Analisys and Research, 2002. Disponível em: <http://www.internationalbudget.org/themes/ESC/FullReport.pdf>. Acesso em: 02 fev. 2014.

SILVEIRA, Fernando Gaiger; OSÓRIO, Rafael Guerreiro; PIOLA, Sérgio Francisco. Os gastos das famílias com saúde. Ciência \& Saúde Coletiva, n. 7, n. 4, p. 719-731, 2002.

SOARES, Hector Cury. A justiciabilidade do direito prestacional à saúde e os critérios para o controle jurisdicional à luz da Constituição Federal de 1988. Tese (Doutorado em Direito Público)- Universidade Federal do Rio Grande do Sul, 2014.

SOARES, Hector Cury. Não levando os custos dos direitos a sério: o direito prestacional à saúde pelo Supremo Tribunal Federal. Revista de Direito Sanitário, v. 16, n. 2, p. 29-51, jul./out. 2015.

SOARES, Hector Cury. O direito ao fornecimento gratuito de medicamentos e políticas públicas: tensões entre o Poder Executivo e o Poder Judiciário. Revista Âmbito Jurídico, n. 76, maio 2010. Disponível em: <http://www.ambito-juridico.com.br/site/index.php/www.inverbis.com.br?n_ link=revista_artigos_leitura\&artigo_id=7748\&revista_caderno=4 >. Acesso em 14 dez. 2016.

SUNSTEIN, Cass R. Direitos Sociais e Econômicos? Lições da África do Sul. In: SARLET, Ingo Wolfgang. Jurisdição e Direitos Fundamentais. Porto Alegre: Livraria do Advogado, 2006. v. I, t. II.

TORRES, Ricardo Lobo. Tratado de direito tributário e financeiro (O Orçamento na Constituição). Rio de Janeiro: Renovar, 2000. v. 5.

TRINDADE, Antônio Augusto Cançado. A proteção internacional dos direitos humanos: fundamentos jurídicos e instrumentos básicos. São Paulo: Saraiva, 1991.

TRINDADE, Antônio Augusto Cançado. Tratado de direito internacional dos direitos humanos. Porto Alegre: Sérgio Fabris, 1997. 
UNITED NATIONS. Committee on Economic, Social and Cultural Rights. General Comment n. ${ }^{\circ}$ 3. Item n. ${ }^{\circ}$ 9. Disponível em: <http://www1.umn.edu/humanrts/gencomm/epcomm3.htm>. Acesso em: 27 fev. 2014.

VIEIRA DE ANDRADE, José Carlos. Os Direitos Fundamentais na Constituição Portuguesa de 1976. Coimbra: Almedina, 2012.

Data da submissão: 13 de janeiro de 2017 Avaliado em: 04 de abril de 2017 (AVALIADOR A) Avaliado em: 09 de abril de 2017 (AVALIADOR B) Aceito em: 13 de abril de 2017 